\title{
Obezite Yönetiminde Sağlık İnanç Modelini Kullanma ve Hemşirenin Rolü
}

\author{
Using the Health Belief Model in Obesity Management and the Nurse's Role
}

\author{
Süheyla YARALI ${ }^{1}$, Nazlı HACIALİOĞLU ${ }^{2}$
}

\begin{abstract}
ÖZ
Obezite gelişmiş ve gelişmekte olan ülkelerde sıklığı gittikçe artan önemli bir sağlık sorunudur. S1k görülmesinin yanında hipertansiyon ve diyabet gibi fiziksel hastalıklara; depresyon ve anksiyete gibi psikolojik sorunlara neden olabilmekte; hastalık ve ölüm oranlarını artırarak yaşam kalitesini ve süresini olumsuz yönde etkilemektedir. Obezite hem neden olduğu ölümler hem de kronik hastalık olması nedeniyle iş gücünde azalma ve sağlık harcamalarında artışa neden olarak ülke ekonomisini etkilemektedir. Günümüzde obeziteye ilişkin riskleri azaltmada obezite yönetiminin gerekli olduğu vurgulanmaktadır. Obezite yönetiminde öncelikle yaşam tarzı değişikliklerinin uygulanması önerilmektedir. Uygun yaşam tarzı değişikliklerini düzenlemede hemşirenin eğitici rolü önemlidir. Eğitimlerin etkili olması için eğitim stratejileri yanında eğitime rehberlik edecek nitelikli bakım modellerinin kullanılması gereklidir. Sağlık inanç modeli, olumsuz yaşam tarzlarını değiştirmede kullanılan etkin bir rehber olarak açıklanmaktadır. Bu makalede; obezite yönetiminde “Sağlık İnanç Modeli”nin kullanımının önemi ve hemşirenin rolü vurgulanmıştır.
\end{abstract}

Anahtar Kelimeler: Obezite Yönetimi, Sağlık İnanç Modeli, Eğitim, Hemşirelik.

\begin{abstract}
Obesity is an important health problem with a gradually increasing incidence in developed and developing countries. In addition to being common, obesity can cause physical diseases such as hypertension and diabetes, psychological problems such as depression and anxiety, and negatively affects quality of life and longevity by increasing mortality and morbidity rates. Obesity affects the country's economy by both resulting deaths and decrease in the labor force and an increase in health spending due to its nature as a chronic disease. Today, it is emphasized that obesity management is necessary to reduce the risks associated with obesity. It is recommended to implement lifestyle changes primarily in obesity management. The nurse's educator role is important in organizing appropriate lifestyle changes. It is necessary to use qualified care models to guide training as well as training strategies in order for training to be effective. The health belief model is described as an effective guide for changing negative lifestyles. This article; The importance of using the "Health Belief Model" and the role of the nurse in obesity management are emphasized.
\end{abstract}

Keywords: Obesity Management, Health Belief Model, Education, Nursing.

\footnotetext{
${ }^{1}$ Araş. Gör. Dr. Süheyla YARALI , Halk Sağlığı Hemşireliği, Atatürk Üniversitesi Hemşirelik Fakültesi, suheyla_sy@hotmail.com ORCID: 0000-0002-7885-1724

${ }^{2}$ Doç. Dr. Nazlı HACIALİOĞLU , Halk Sağlığı Hemşireliği, Atatürk Üniversitesi Hemşirelik Fakültesi, nazli@ atauni.edu.tr ORCID: 0000-0001-9758-0790 


\section{GíRiş}

Obezite genetik faktörler, hormonal bozukluklar, metabolik sorunlar, beslenme, fiziksel aktivite düzeyi, psikolojik sorunlar, sosyo-ekonomik durum gibi birçok faktör ve diğer sağl1k problemlerinin kişide bulunmasından etkilenen multifaktöriyel bir hastalıktır. ${ }^{1,2}$

Önceleri yalnızca estetik ve beden imajı açısından bir sorun olarak görülen obezite günümüzde fizyolojik ve psikolojik birçok sağlık problemine neden olarak yaşam kalitesini olumsuz yönde etkileyen ve süresini kısaltan kronik bir hastalık olarak kabul edilmektedir. ${ }^{2}$ Özellikle gelişmiş ve gelişmekte olan ülkelerde giderek artan obezite birçok sağlık problemine neden olduğu için önemli bir halk sağlığı sorunu haline gelmektedir. ${ }^{3} \mathrm{Bu}$ durum obezitenin önlenmesi, yönetilmesi ve tedavi edilmesinin sağlık açısından önemli olduğunu ortaya koymaktadır. Obezitede tedavinin sağlanabilmesi için, içinde hemşirelerinde yer aldığ multidisipliner yaklaşım son derece önemlidir. ${ }^{2,3}$

Hemşireler; bireyin, ailenin ve toplumun sağlığını sürdürmede bireylerle en sık karşılaşan sağlık çalışanı olma özelliklerinden dolayı obeziteye yönelik multidisipliner yaklaşımda kilit rol oynamaktadır. ${ }^{4}$ Hemşirelerin obezite ile mücadele için önleme, yönetme ve tedavide önemli sorumlulukları bulunmaktadır. Hemşire bu sorumluluklarını yerine getirmede çoğunlukla eğitimci rolü ön plana çıkmaktadır. ${ }^{5,6} \mathrm{Bu}$ nedenle hemşirenin verdiği eğitimin etkili olabilmesi için eğitimin sadece bilişsel alana yönelik değil, duyuşsal ve psikomotor öğrenme alanlarına göre de yapılandırılarak, eğitime rehberlik edecek etkin bakım modelleri çerçevesinde verilmesi gerekmektedir., ${ }^{4,7} \mathrm{Bu}$ makalede "Sağlık İnanç Modeli"ni (SİM) obezite yönetiminde kullanmanın önemi ve hemşirenin rolü vurgulanmıştır.

\section{Obezitenin Tanımı}

Dünya Sağlık Örgütü (DSÖ) obeziteyi, sağlığı bozacak ölçüde vücutta aşırı yağ birikmesi olarak tanımlanmaktadır. ${ }^{1}$

Obezitenin belirlenmesinde beden kitle (BKİ) indeksi en sık kullanılan yöntemdir. [BKİ=Ağırlık $\quad(\mathrm{kg}) \quad /$ Boy $\quad\left(\mathrm{m}^{2}\right)$ ] formülü kullanılarak hesaplama yapılmaktadır. Sonuca göre; BKI'nin $30 \mathrm{~kg} / \mathrm{m}^{2}$ ve üzerinde olduğu değerler obezite olarak kabul edilmektedir. Buna göre 30 ve üzerindeki değerlerin obezite olarak kabul edildiği Tablo 1 'de detayları sunulmuştur. ${ }^{1}$

Tablo 1. BKI'ye Göre Obezite Sınıflaması ${ }^{1}$

\begin{tabular}{ll}
\hline Sınıflandırma & $\begin{array}{l}\text { BKİ }\left(\mathbf{k g} / \mathbf{m}^{\mathbf{2}}\right) \\
\text { Temel Kesişim } \\
\text { Noktaları }\end{array}$ \\
\hline Zayıf (düşük ağırlıklı) & $<\mathbf{1 8 , 5 0}$ \\
\hline Aşırı düzeyde zayıflık & $<16,00$ \\
\hline Orta düzeyde zayıflık & $16,00-16,99$ \\
\hline Hafif düzeyde zayıflık & $17,00-18,49$ \\
\hline Normal & $\mathbf{1 8 , 5 0 - 2 4 , 9 9}$ \\
\hline Fazla kilolu & $\geq 25,00-29,99$ \\
(Preobez) & $\geq \mathbf{3 0 , 0 0}$ \\
\hline Obez & $30,00-34,99$ \\
\hline Obez I. Derece & $35,00-39,99$ \\
\hline Obez II. Derece & $\geq \mathbf{4 0 , 0 0}$ \\
\hline Obez III. Derece
\end{tabular}




\section{Obezitenin Görülme Sıklığı}

Dünya Sağlık Örgütü (DSÖ) 2016 yılında 650 milyondan fazla yetişkinin obez olduğunu belirlemiştir. Dünya çapında obezite prevalansının 1975 yılından bu yana yaklaşık üç katına çıktığı ve görülme sıklığının giderek artmakta olduğu dikkat çekmektedir. ${ }^{8}$

Obezite sıklığı Amerika Birleşik Devletleri DSÖ Bölgelerinde \%36,2 oranıla en yüksek, Güney Doğu Asya DSÖ Bölgesi'nde \%36 oranıyla en düşük seviyede görülmektedir. ${ }^{8}$

Ekonomik Kalkınma ve İşbirliği Örgütü (OECD) ülkelerinde 15 yaș ve üzeri nüfusta obezite oranının \%19,5 olduğu, \%38,2 obezite oraniyla ABD'nin en yüksek, Japonya'nın ise \%3,7 oranıyla en düşük obezite oranına sahip olduğu görülmüștür. Türkiye'nin, \%22,3'lük obezite oranıla OECD ülkeleri arasında 13. sırada yer aldığ ve \%19,5 olan OECD ortalamasının üstüne çıktığı görülmektedir. ${ }^{9}$

Dünya Sağl1k Örgütü 2016 verilerine göre ülkemizdeki yetişkin nüfusun $\% 32,1$ 'inin obezite hastası olduğu görülmektedir. ${ }^{8}$ Bulaşıcı Olmayan Hastalıkların Risk Faktörleri Prevalansı 2017 (STEPS) sonuçlarına göre erişkinlerde toplam nüfusun $\% 28,8$ 'nin obezite hastasi olduğu bulunmuştur. ${ }^{10}$

Yapılan açıklamalardan da anlaşıldığı gibi obezite tüm dünyada önemli boyutlara ulaşmış durumdadır. Obezitenin görülme sıklığını azaltmak için obeziteye neden olan faktörlerin bilinmesi gereklidir.

\section{Obeziteye Neden Olan Faktörler}

Obezite oluşum nedenlerine göre primer ve sekonder obezite olarak ikiye ayrılır. Yaş, genetik faktörler, cinsiyet, fiziksel aktivite, beslenme alışkanlıkları, sosyoekonomik durum, kültürel çevre ve psikolojik etkiler gibi birçok faktör primer obezitenin nedenleri arasındadır. Sekonder obezite ise Cushing hastalığ1, Polikistik Over Sendromu ve Hipotiroidizm gibi nöroendokrin nedenler, kortikosteroidler, antidepresanlar gibi ilaçlar, Down Sendromu, Wilson-Turner Sendromu gibi nadir genetik sendromlara bağlı olarak meydana gelir. Sekonder obezite, hastaların küçük bir bölümünü oluştururken primer obezite $\% 95$ 'ini oluşturmaktadır. ${ }^{2}$

Primer obezite nedenleri arasında yer alan fiziksel aktivite yetersizliği, yanlış ve dengesiz beslenme önemli ve değiştirilebilir faktörlerdendir. ${ }^{2}$

Güncel araştırmalar; teknolojinin getirdiği televizyon ve bilgisayar karşısında uzun zaman geçirme, buna bağlı olarak düzensiz ve dengesiz beslenme gibi yaşam şeklindeki değişimlerin obezitenin ortaya çıkmasında önemli olduğunu açıklamaktadır. ${ }^{3} \mathrm{Bu}$ nedenle obezite hastası bireylerde fiziksel aktivite ve beslenme alışkanlıklarının olumlu yönde değiştirilmesi önem kazanmaktadır. Gerekli önlemler zamanında alınarak obezite doğru bir şekilde yönetilmez ise ilerleyerek morbid seviyeye ulaşıncaya kadar çok ciddi sağlık sorunlarına neden olabilir. ${ }^{11,12}$

\section{Obezitenin Neden Olduğu Sorunlar}

Obezite, kalp damar hastalıkları, hipertansiyon, diyabet, kas iskelet sistemi hastalıkları, bazı kanser türleri ve solunum sistemi hastalıkları gibi birçok hastalığın oluşmasına neden olmakta; hastalık ve ölüm oranlarını artırarak, yaşam kalitesi ve süresini olumsuz yönde etkilemektedir. ${ }^{11,12}$

Obezite sadece fiziksel hastalıklara değil, aynı zamanda ruhsal, sosyal ve ekonomik alanlarda da problemlere neden olmaktadir. Obez bireyler işyerleri, eğitim ve kişisel ilişkiler gibi hayatın birçok alanında, toplumsal önyargılar nedeniyle öfke, suçlama gibi olumsuz davranışlara maruz kalmaktadır. $\mathrm{Bu}$ durum düşük beden imajı, benlik saygısında azalma, depresyon ve anksiyete gibi psikolojik sorunlara neden olabilmektedir. ${ }^{13,14}$

Artan obezite oranları toplum sağlı̆̆ını olumsuz etkilemenin yanında işgücü kaybına da neden olmakta ve kamu sağlik harcamaları üzerindeki yükü de artırmaktadır. $^{12,15}$ Bütün bu açılardan bakıldığında; obezite, birey, aile ve ülke 
ekonomisine büyük zararlar veren bir sağlık sorunu olarak karşımıza çıkmaktadır ve obezitenin yönetimi bireyin, toplumun ve ülkenin yaşadığı sorunların önlenmesinde kilit rol oynamaktadır.

\section{Obezite Yönetimi}

Obezite yönetimi, kilo verme, kilo veremeyen kişilerde daha fazla kilo alımını önleme ve obezite nedeniyle oluşabilecek sağlık risklerinde azalma sağlamak için yapılan girişimlerdir. ${ }^{16}$ Amaç, bireyin hastalık ve ölüm riskini azaltarak yaşam kalitesini yükseltmektir. Bu amaca ulaşmak için bireyde gerçekçi bir vücut ağırlığı kaybı olan ağırlığının \%10'luk kısmının 6 aylık bir süre içinde kaybedilmesi hedeflenmelidir. ${ }^{2,17}$

Obezite yönetimi için uygulanacak girişimler sağlıklı yaşam tarzı oluşturma ve tıbbi tedavi olmak üzere iki temel yönteme dayanır. ${ }^{18}$ Yaşam tarzı değişikliklerine yönelik yapılan çalışmalarda ağırlık kaybına yönelik olumlu sonuçlar bulunmuştur. ${ }^{19,20,}$ Bu nedenle bireye doğru beslenme ve fiziksel aktivite alışkanlıklarının kazandırılması bu konuda kilit noktayı oluşturmaktadır.

Obezitenin kontrol altına alınmasında hastanın eğitimi ve motivasyonu önemlidir. Obezite yönetimi yeni bir yaşam modeli oluşturmayı içerir. $\mathrm{Bu}$ nedenle girişimler mutlaka beslenme ve egzersiz alışkanlıklarını içeren yaşam tarzı değişikliklerini kapsamalıdır. ${ }^{21}$ Obezite yönetiminde yaşam tarzı değişikliklerini sağlamada hemşirelerin multidisipliner grup içerisinde önemli rolleri bulunmaktadır. 6,7

\section{Obezite Yönetiminde Hemşirenin Rolü}

Hastaya uygulanacak tedavi stratejilerinin hepsinde hekim, hemşire, beslenme uzmanı, psikolog ve psikiyatrist, spor hekimi, fizyoterapist, okul hemşiresi, öğretmenler ve ailenin yer aldığ son derece önemlidir. Obezite tedavisi yeni bir yaşam modeli oluşturmayı içerdiği için tedavi programının tüm aşamalarında eğitim son derece önemli hale gelmektedir. ${ }^{2}$
Obezite yönetiminde bireylerin yaşam tarzı değişikliği yapabilmelerinde hemşire eğitimci rolünü kullanarak etkin olmaktadır. Obezite yönetimini doğru bir şekilde yönetebilmek için; hastadan ve ailesinden öykü almak, kültürel davranışlar ve ekonomik kaynakları araştırmak, bütüncül bir yaklaşımla topladığı verileri analiz ederek bilgi, tutum, beceri ve davranış alanlarına yönelik gereksinim belirlemek, gereksinim alanlarına göre eğitimin hedeflerini hastayla birlikte belirlemek, yapabilecekleriyle ilgili hastayı cesaretlendirmek, olumlu düşünmeyi sağlamak ve motive etmek hemşirenin görevleri arasında yer almaktadır. ${ }^{21,22}$

Hemşirelikte modeller, meslekle ilgili kavramları belirleyerek, belirlediği kavramlar arasındaki ilişkiyi açıklar. Hemşirelik modelleri, bireyi odak noktası olarak düşünür ve tüm hemşirelik girişimlerinin mesleksel boyut çerçevesinde ele alınmasını sağlar. Modeller hemşirelik bilgisini, yapılan girişimleri ve uygulamaları sistematik bir çerçevede sürdürmeyi sağlayarak hemşirelere rehberlik eder ve tüm süreçlerde profesyonel iletişim sağlar. ${ }^{7}$ Sağlık İnanç Modeli'nin obeziteyi etkin bir şekilde yönetebilmek için değiştirilebilir faktörler üzerinde etkinliği kanıtlanmıştır. ${ }^{19,20}$

\section{Sağlık İnanç Modelinde Kavramsal Çerçeve}

Sağlık İnanç Modeli 1950'li yıllarda Hochbaum, Rosenstock ve Kegels tarafindan geliştirilmiştir. $^{24} 1966$ yılında Rosenstock, 1975 yılında Becker tarafindan revize edilmiştir. $^{25,26}$ SİM bireyin sağlığa ilişkin doğru davranışları yapmaya veya yapmamaya neden olan durumları anlama üzerine temellenmiştir. Model birçok çalışmada kullanılmış ve geçerliliği kanıtlanmıştır. ${ }^{27-29}$ Sağlik İnanç Modelinin duyarlılık, ciddiyet, yarar ve engel algis1 olarak dört temel boyutu belirlenmiş; 1988 y1lında modele öz etkililik boyutu eklenmiştir. ${ }^{30}$ Sağlık motivasyonu, eyleme geçme olasılığı ve davranışın etkinliği de SİM temelli çalışmaların bazılarında yer almaktadır. $^{31}$ 


\section{Duyarlılık Algısı}

Bireyin sağlığını tehdit eden hastalıkla ilgili algisıdır. Birey kendini risk altında hissettiği durumda risk oluşturacak davranışı yapmaktan kaçınacaktır. Bu nedenle riskli davranıştan kaçınmada bireyin kendini risk altında hissetme durumu önemsenmelidir. ${ }^{31}$

$\mathrm{Bu}$ aşamada bireyler hastalığı hakkında bilgilendirilerek hastalığın riskleri konusunda farkındalık oluşturulup duyarlıklıları artırılmalıdır.

\section{Ciddiyet Algısı}

Bireyin meydana gelebilecek hastalığa yönelik karşılaşacağı sorunları ve bunların ciddiyetini nasıl algıladığıdır. Ciddiyet algısında bireyin hastalığın önemi ve nasıl oluştuğu hakkında bilgi sahibi olması ciddiyet algısını etkilemektedir. ${ }^{31} \mathrm{Bu}$ aşamada oluşturulacak eğitim içeriği söz konusu durumlar göz önüne alınarak planlanmalıdir.

\section{Yarar Algısı}

Bireyin sağlığa ilişkin doğru davranışı yapmasının sonrasında hastalığa yakalanma riskinin azalacağı ile ilgili algıdır. ${ }^{31}$ Eğitim içeriklerinde risklerin azalmasına yönelik geçmişte yaşanan örnekler ve deneyimler paylaşılmalıdır.

\section{Engel Algisı}

Bireyin hastalığın risklerine yönelik yeni edineceği davranışları uygulama konusunda bireysel olarak algılanan engellerdir. ${ }^{31}$ Eğitim planlarında veri toplama aşamasında bireye özgü belirlenen engellerin nasıl aşılacağı konusunda etkinlere yer verilmelidir.

\section{Öz Etkililik}

$\begin{gathered}\text { Bireyin davranışlarına } \\ \text { edebileceği }\end{gathered}$ ve büdahale
gerçekleştirdiğinde başarılı olabileceğine dair
davranışı
inancı öz
etkililiği yüliliği oluşturmaktadır. Öz
gerçekleştireceğine ve bu durumun onlara
yarar sağlayacağına inandikları için öz

etkililiği düşük bireylere göre daha kolay eyleme geçmektedirler. ${ }^{31} \mathrm{Bu}$ nedenle bireylerin öz etkililikleriyle ilgili veriler toplanarak değerlendirilmeli ve eğitim içeriklerinde bireylerin öz etkiliklerini yükseltecek girişimlere yer verilmelidir.

\section{Sağlık Davranışı Kazandırmada Sağlık İnanç Modelinin Kullanımı}

Modeller, uygulanacak girişimlerin geliştirilerek test edilmesine yol göstermekte ve girişimlerin sonuçlarının bilimsel boyutta ortaya koyulmasını sağlamaktadır. ${ }^{32}$

Modeller bireylerin davranışlarını etkileyebilecek faktörleri bir araya getirerek, bir bütün olarak görmeyi ve amaca ulaşmak için izlenecek yolları belirlemeyi sağlar. Bu nedenle hemşirelik alanında girişimsel uygulamalara standart bir yaklaşım oluşturmak için modellerin kullanımı son zamanlarda daha çok artmış durumdadır. Hemşirelik uygulamalarında en sık kullanılan modellerden biri SIMM'dir. ${ }^{7,33}$

Bireylerin sağlık davranışlarının inanç, değer ve tutumlarından etkilenerek ortaya çıktığını ifade eden SİM, bireylerde sorun olarak tespit edilen inanç ve tutumların bu durumlara yönelik etkin eğitimlerle olumlu yönde değiştirilebileceğini göstermektedir. Meme Kanseri ve taramaları, Serviks Kanseri ve taramaları, Diyabet yönetimi, Osteoporoz, Kolorektal Kanser taramaları gibi birçok sağlık problemine yönelik SİM rehberliğinde yapılan çalışmada sağlık problemleri üzerinde olumlu değişimler görülmüştür. ${ }^{31}$

Obezitenin önlenmesi ve yönetiminde beslenme ve fiziksel aktivite gibi değiştirilebilir faktörler önemli rol oynamaktadır. $\mathrm{Bu}$ nedenle obezite ile mücadelede planlanacak eğitimlerin, SİM'ye göre yapılandırılarak verilmesi olumlu sağlık davranışları geliştirmede önemli sonuçlar elde edilmesini sağlayabilir. ${ }^{34}$

\section{Obezitede Sağlık İnanç Modelinin Kullanımı}

Obezite yönetiminde SIM'ye göre yapılandırılmış eğitim programlarıyla yapılan 
çalışmalarda inanç ve davranışlar olumlu yönde değişerek BKI'de düşüş sağlanmıştır. ${ }^{19,20,34}$ araç gereçleri alanlarını kapsayan eğitim örneği planı Tablo 2'de yer almaktadır. ${ }^{34}$

Tablo 2. Obezite Yönetiminde Sağlık İnanç Modeline Yönelik Eğitim Örneği. ${ }^{34}$

\begin{tabular}{|c|c|c|}
\hline Eğitim Konusu & $\begin{array}{l}\text { Eğitim } \\
\text { Yöntemleri }\end{array}$ & $\begin{array}{l}\text { Eğitim } \\
\text { Araç-gereçleri }\end{array}$ \\
\hline \multicolumn{3}{|l|}{ Obeziteye Yönelik Duyarlılık Algısı } \\
\hline $\begin{array}{l}\text { Obezitenin tanımı, s1klığı ve nedenleri } \\
\text { Obezitenin önlenmesi ve önemi } \\
\text { Obezite yönetimi ve önemi }\end{array}$ & $\begin{array}{l}\text { Anlatma-Tartışma } \\
\text { Soru-cevap }\end{array}$ & $\begin{array}{l}\text { Power point } \\
\text { sunumu }\end{array}$ \\
\hline \multicolumn{3}{|l|}{ Obeziteye Yönelik Ciddiyet Algısı } \\
\hline $\begin{array}{l}\text { Obezitenin sağlık açısından zararları } \\
\text { Obezitenin neden olduğu fiziksel hastalıklar } \\
\text { Obezitenin neden olduğu ruhsal hastalıklar }\end{array}$ & $\begin{array}{l}\text { Anlatma-Tartışma } \\
\text { Soru-cevap }\end{array}$ & $\begin{array}{l}\text { Power point } \\
\text { sunumu } \\
\text { Yazı Tahtası }\end{array}$ \\
\hline \multicolumn{3}{|l|}{ Obezite Yönetimine İlişkin Yarar Algısı } \\
\hline $\begin{array}{l}\text { Obezite yönetiminde kilo vermenin yararları } \\
\text { Obezite yönetiminde doğru beslenmenin } \\
\text { yararları } \\
\text { Obezite yönetiminde fiziksel aktivitenin } \\
\text { yararları }\end{array}$ & $\begin{array}{l}\text { Anlatma-Tartışma } \\
\text { Soru-cevap }\end{array}$ & $\begin{array}{l}\text { Ĕgitim kitapçı̆̆ } \\
\text { Power point } \\
\text { sunumu }\end{array}$ \\
\hline $\begin{array}{l}\text { Obezite Yönetimine İlişkin Engeller } \\
\text { Obezite yönetiminde karşılaşılan engeller } \\
\text { Obezite hastası bireylerin kilo verme } \\
\text { deneyimlerinin dinlenmesi }\end{array}$ & $\begin{array}{l}\text { Soru-cevap } \\
\text { Vaka sunumu }\end{array}$ & $\begin{array}{l}\text { Power point } \\
\text { sunumu } \\
\text { Yazı Tahtası } \\
\text { Yaşanmış } \\
\text { Hikayeler }\end{array}$ \\
\hline $\begin{array}{l}\text { Obezite yönetiminde karşılaşılan engeller } \\
\text { Obezite hastası bireylerin kilo verme } \\
\text { deneyimlerinin dinlenmesi }\end{array}$ & Vaka sunumu & $\begin{array}{l}\text { Yaşanmış } \\
\text { Hikayeler }\end{array}$ \\
\hline \multicolumn{3}{|l|}{ Obezite Yönetimine İlişkin Engeller } \\
\hline $\begin{array}{l}\text { Düzenli beslenme engelleri ve çözüm } \\
\text { önerileri } \\
\text { Obezite hastası bireylerin beslenme } \\
\text { davranışlarının değerlendirilmesi }\end{array}$ & $\begin{array}{l}\text { Anlatma-Tartışma } \\
\text { Soru-cevap }\end{array}$ & $\begin{array}{l}\text { Power point } \\
\text { sunumu } \\
\text { Yazı Tahtası }\end{array}$ \\
\hline Obezite Yönetimine İlişkin Engeller & & \\
\hline $\begin{array}{l}\text { Fiziksel aktivite engelleri ve çözüm önerileri } \\
\text { Obezite hastası bireylerin fiziksel aktivite } \\
\text { davranışlarının değerlendirilmesi }\end{array}$ & $\begin{array}{l}\text { Anlatma-Tartışma } \\
\text { Soru-cevap } \\
\text { Demonstrasyon }\end{array}$ & $\begin{array}{l}\text { Power point } \\
\text { sunumu } \\
\text { Video gösterisi }\end{array}$ \\
\hline
\end{tabular}

\section{Obezitede Sağlık İnanç Modeline Yönelik Ĕ̆itim İçeriklerinde Kullanılabilecek Iffadeler}

Eğitimde kullanılabilecek ifadeler SİM 'nin temel boyutları olan duyarlılık, ciddiyet, yarar, engel alt boyutlarına göre belirtilmiştir.

\section{Obeziteye Yönelik Duyarlıık Algısı}

Obeziteye yönelik SiM'ye göre oluşturulacak eğitimlerde SİM'nin bu konuda duyarlılık algısını etkileyecek ifade örnekleri aşağıda yer almaktadır. 
- Obezite önlenmediği ve müdahale edilmediği zaman yaşam kalitesini önemli derecede bozan kronik bir hastalıktır. ${ }^{35}$

- Dünya Sağlık Örgütü verilerine göre obezite, Tip 2 diyabet vakalarının yüzde 80'inden, iskemik kalp hastalıklarının yüzde 35 'inden ve hipertansiyonun yüzde 55'inden sorumludur ve her y1l 1 milyondan fazla ölüme neden olmaktadır. ${ }^{35}$

- Obezitenin bireylerin fiziksel, sosyal ve ruhsal sağlığını bozması, yaşam kalitesini olumsuz yönde etkilemektedir. ${ }^{13,14}$

\section{Obeziteye Yönelik Ciddiyet Algısı}

Obeziteye yönelik SİM'ye göre oluşturulacak eğitimlerde SİM'nin bu konuda ciddiyet algısını etkileyecek ifade örnekleri aşağıda yer almaktadır.

- Obezite birçok sağlik problemine zemin hazırlayan tedavi edilebilir bir kronik hastalıktır. Bu nedenle önlenmesi ve tedavi edilmesi gerekmektedir.

- Obezite hastalarında ölümlerin en önemli nedenlerinden biri kalp damar hastalıklarıdır. Obezite kalp yetmezliği ve felç riskini artmaktadır. ${ }^{36}$

- Obezite hastalarında yüksek kolesterol riski normal vücut ağırlığına sahip kişilerle karşılaştırıldığında, 20-25 yaş grubunda 1,5 kat, 20-45 yaş gurubunda da 2,5 kat daha yüksek olduğu görülmektedir. ${ }^{36}$

- Şeker hastalığı gelișme riski obezite hastalarında normal kilodaki bireylere oranla 5-10 kat daha fazla olmaktadır. ${ }^{12}$

- Obezite hastalarında sik kilo alıp vermeye bağlı olarak deri enfeksiyonları daha fazla görülmektedir. ${ }^{37}$

- Obezite hastalarında ruhsal sorunlara daha s1k rastlanmaktadır. ${ }^{38}$

- Obezite hastaları iş bulamama ve dışlanma gibi sorunları daha sik yaşamaktadır. ${ }^{39}$

\section{Obezite Yönetimine İlişkin Yarar Algısı}

Obeziteye yönelik SİM'ye göre oluşturulacak eğitimlerde SİM'nin bu konuda yarar algısını etkileyecek ifade örnekleri aşağıda yer almaktadır.

Obezite yönetimi için beslenme ve fiziksel aktivite konusunda davranış değişikliği ile kilo kontrolü sağlayabilirseniz;

- Sağliklı bir bedene sahip olursunuz.

- Hastalıklara yakalanma riskiniz azalır.

- Yüksek tansiyon, şeker hastalığı, kalp hastalıkları, kanser, mide hastalıkları, adet düzensizlikleri, uyku sorunları, ruhsal sıkıntılar, sosyal ilişkilerde bozulma gibi birçok fiziksel, ruhsal ve sosyal sorunlarınızın ortaya çıkmasında riskiniz azalır.

- Obeziteden kaynaklı vücuttaki kemik, eklem ve kaslarınızda olan ağrılarınız azalır.

- Daha az fiziksel (düşme vb.) kazaya mağruz kalırsınız.

- Daha hareketli ve esnek bir vücuda sahip olursunuz.

- Uygun vücut ölçülerine sahip olarak daha mutlu ve kendine güvenli hissedersiniz

- Fiziksel görünüşünüzü aynada beğenerek mutlu olursunuz.

- Beğendiğiniz k1yafetlerin bedenlerini bulup alarak daha mutlu hissedersiniz. ${ }^{40}$

\section{Obezite Yönetimine İlişkin Engel Algısı}

Obeziteye yönelik SìM'ye göre oluşturulacak eğitimlerde SİM'nin bu konuda engel algısını etkileyecek ifade örnekleri aşağıda yer almaktadır. Bu ifadeler eğitim verilen bireyin yaşadığ 1 yer, kültürel özellikler, çalışma yaşantısı gibi özelliklerine göre farkl1lıklar göstermektedir.

- Diyetisyenlere başvurarak sizlere önerilen beslenme programlarını kullanmanız doğru beslenmenizi sağlar.

- Akraba ve komşularınızla tarafından davet edildiğinizde sağlığınız için az 
yemeniz gerektiğini belirtmeniz tüketeceğiniz besinleri sınırlandırmanızı sağlar.

- Alışverişe tok karna çıkmak daha az ürün satın almanızı sağlar.

- Öğün atlamamak bir sonraki öğünde aşırı besin tüketmenizi engeller.

- Satın aldığınız ürünlerin daha düşük kalorili olanını tercih etmeniz (yağsız peynir gibi) az kalori almanızı sağlar.

- Göz önünde atıştırmalık yiyecekler bulundurmamak yemenizi engeller.
- $\mathrm{Su}$ içmek için bardak yerine şişe kullanmalıyız; çünkü içtiğiniz suyun miktarını bilmeniz su tüketiminizi takip edebilmenizi sağlar.

- Ev işleri yapmanın fiziksel hareket olarak yeterli olduğu düşüncesini aklımızdan çıkarmalıyız.

- Günde en az 30 dk'lık orta şiddette bir fiziksel aktivite yapmak (yürüyüş gibi) günlük rutinleriniz arasında olsun ve bunu alışkanlık haline getirmeliyiz. ${ }^{40}$

\section{SONUÇ VE ÖNERILER}

Sonuç olarak; obezite hastası bireylere SİM'ye göre verilen eğitimin bireylerin obeziteye yönelik inançlarını olumlu yönde değiştirmede ve obezite yönetimi sağlamada etkili bir model olduğu, modelin kullanımının hemşirelerin daha sistematik ve planlı eğitim vermesini sağlayarak obezite yönetiminde etkili sonuçlar oluşturacağı söylenebilir. Bu sonuçlar doğrultusunda;

Obezite ve obeziteye bağlı gelişebilecek sağlık sorunlarını önlemede hemşirelerin planlayacakları eğitimleri SİM'ye göre yapılandırmaları,
Hemşirelerin obezite yönetiminde SİM'yi kullanabilmeleri için model hakkında bilgilendirilmeleri,

Hemşirelik eğitiminin her düzeyinde, model temelli eğitim planlamaları hakkında bakış açısı kazandırılması,

Sağlığın korunması ve geliştirilmesi için eğitim yapan halk sağlığ obezite yönetimine yönelik SIM temelli eğitim programları oluşturmaları önerilebilir.

\section{KAYNAKLAR}

1. Prevention and management of the global epidemic of obesity. Report of the WHO Consultation on Obesity (Geneva, June, 35, 1997). Geneva: WHO. file:///C:/Users/tr/Documents/ Downloads/WHO_NUT_NCD_98.1_(p1-158).pdf (ET: 20.03.2020).

2. Aygün M. (2012). Obezite ve Yönetimi. İçinde: Durna Z (Editör). Kronik Hastalıklar ve Bakım, İstanbul: Nobel Matbaac1lık, 341-378.

3. Tedik, SE. (2017). "Fazla Kilo/Obezitenin Önlenmesinde ve Sağlıklı Yaşamın Desteklenmesinde Hemşirenin Rolü." Türkiye Diyabet ve Obezite Dergisi, 2, 54-62

4. Hacialioğlu N. (2013) Hemşirelikte Öğretim, Öğrenme ve Eğitim, İstanbul: Nobel Tip Kitabevi. 1-16.

5. Yeșilfidan, D, Adana, F. (2019). "Halk Sağlığı Hemșireliği Bakış Açısı ile Ergenlerde Obezite." Hemşirelik Bilim Dergisi, 2 (2), $38-44$.

6. Erdim, L, Ergun, A, Kuğuoğlu, S. (2014). "Cocuklarda Obezitenin Önlenmesi Ve Yönetiminde Hemşirenin Rolü." Sağlık Bilimleri ve Meslekleri Dergisi, 1 (2), 115-126.

7. Ak, KV. (2010). "Hemșirelik bakımında model kullanımına bir örnek: Modifiye radikal mastektomi olmuş bir bayanın, Roy'un adaptasyon modeline göre incelenmesi." Maltepe Üniversitesi Hemşirelik Bilim ve Sanatı Dergisi, 3 (2), 107-118.
8. World Health Organization. Obesity and overweight Fact Sheet. http://www.who.int/news-room/fact-sheets/detail/obesity-andoverweight. (ET:17.07.2020).

9. OECD. Obesity Update. http://www.oecd.org/health/healthsystems/obesity-update.htm. (ET:24.07.2018).

10. Türkiye Hanehalkı Sağlık Araştırması: Bulaşıcı Olmayan Hastalıkların Risk Faktörleri Prevalansı 2017 (STEPS). Editörler: Üner S, Balcılar M, Ergüder T. Dünya Sağlık Örgütü Türkiye Ofisi, Ankara, .2018, 103.

11. Halk Sağlığg Genel Müdürlüğü. Obezite Diyabet ve Metabolik Hastalıklar Daire Başkanlığı, Obezitenin Yol Açtı̆̆ Problemleri https://hsgm.saglik.gov.tr/tr/obezite/obezitenin-yolactigi-saglik-problemleri.html (ET:13.03.2020).

12. Türkiye Endokrinoloji ve Metabolizma Derneği. (2019). Obezite Tanı ve Tedavi Kılavuzu Ankara: BAYT Bilimsel Araştırmalar Basın Yayın.

13. O'Brien, KS, Latner, JD, Puhl, RM, Vartanian, LR, Giles, C, Griva, K, Carter, A. (2016). "The relationship between weight stigma and eating behavior is explained by weight bias internalization and psychological distress." Appetite, 102, 7076.

14. Phelan, SM, Burgess, DJ, Yeazel, MW, Hellerstedt, WL, Griffin, JM, Van Ryn, M. (2015). "Impact of weight bias and stigma on quality of care and outcomes for patients with obesity." Obesity Reviews, 16 (4), 319-326. 
15. Cukur, A, Arıtı, Eİ. (2017). “Obezite Vergilerinin Obezite ile Mücadelede Yeri: Türkiye için Bir Değerlendirme.” Sayıştay Dergisi, 28 (106), 121-139.

16. Yumuk, V, Tsigos, C, Fried, M, Schindler, K, Busetto, L, Micic, D, Toplak, H. (2015). "European guidelines for obesity management in adults." Obesity facts, 6 (8), 402-424.

17. T.C. Sağlık Bakanlığı Halk Sağlığı Genel Müdürlüğü Sağlıklı Beslenme ve Hareketli Hayat Dairesi Başkanlığı. Obezite Tedavisi. https://hsgm.saglik.gov.tr/tr/obezite/obezitenintedavisi.html. (ET:23.07.2020).

18. Orhan, Y. Şişmanlık. İçinde: Sencer E (editör). (2001) Endokrinoloji, Metabolizma ve Beslenme Hastalıkları İstanbul: Nobel Tip Kitabevleri, 716-733.

19. Romano, V, Scott, I. (2014). "Using health belief model to reduce obesity amongst African American and Hispanic populations." Procedia-Social and Behavioral Sciences, 159, 707-711.

20. Khumros, W, Vorayingyong, A, Suppapitiporn, S, Rattananupong, T Lohsoonthorn, V. (2019), "Effectiveness of modified health belief model-based intervention to reduce body mass index for age in overweight junior high school students in Thailand." Journal of Health Research, 33 (2), 162-172.

21. Yeşilfidan, D, Adana, F. (2019). "Halk Sağlığı Hemşireliğ Bakış Açısı ile Ergenlerde Obezite.” Hemşirelik Bilim Dergisi, 2 (2), 38-44.

22. Dedeli, Ö , Fadiloğlu, Ç. (2012). “Obezitede güçlendirme ve hemşirelik yaklaşımları.” Türkiye Klinikleri Journal of Nursing Sciences, 2 (4), 94-101.

23. Tyler, C , Johnston, CA , Foreyt, JP. (2007). "Themed Review: Lifestyle Management of Obesity." American Journal of Lifestyle Medicine, 1 (6), 423-429.

24 University of Twente. Health Belief Model. https://www.utwente.nl/en/bms/communication-theories/sortedby-cluster/HealthCommunication/Health-Belief-Model/..pdf. (ET: 22.07.2020).

25. Rosenstock, IM. (1974). "Historical origins of the health belief model." Health education monographs, 2 (4), 328-335.

26. Becker, MH. (1974). "The health belief model and sick role behavior." Health education monographs, 2 (4), 409-419.

27. Pirzadeh, A, Mazaheri, MA. (2012). "The effect of education on women's practice based on the health belief model about pap smear test." International journal of preventive medicine, 3 (8), 585 .
28. Plawecki, K, Chapman-Novakofski, K. (2013). "Effectiveness of community intervention in improving bone health behaviors in older adults." Journal of nutrition in gerontology and geriatrics, 32 (2), 145-160.

29. Ma, GX , Gao, W , Fang, CY , Tan, Y , Feng, Z , Ge, S , Nguyen JA. (2013). "Health beliefs associated with cervical cancer screening among Vietnamese Americans." Journal of Women's Health, 22 (3), 276-288.

30. Champion, VL. (1999). "Revised susceptibility, benefits, and barriers scale for mammography screening." Research in Nursing \& Health, 22 (4), 341-348.

31. Gözüm, S , Çapık, C. (2014). "Sağlık davranıșlarının geliştirilmesinde bir rehber: sağlık inanç modeli.” Dokuz Eylül Universitesi Hemşirelik Fakültesi Elektronik Dergisi, 7 (3), 230-237.

32. Şengün, F , Üstün, B , Bademli, K. (2013). "Türkiye'de Kuram/Modele Dayali Hemşirelik Araștırmalarının İncelemesi." Journal of Anatolia Nursing and Health Sciences, $16(2), 132-139$.

33. Ekim, A , Manav, G , Ocakçı, AF. (2012). "Ülkemizde teori temelli hemşirelik araştırmaları: Bir gözden geçirme.” Dokuz Eylül Üniversitesi Hemşirelik Yüksekokulu Elektronik Dergisi, $5(4), 157-161$.

34. Yaralı, S. (2018). “Obez Kadınlara Sağlık İnanç Molinede Göre Verilen Eğitimin Kadınların Obeziteye Yönelik İnançlarına ve Obezite Yönetimine Etkisi" (doktora Tezi). Yök. Tez. (529858).

35. Halk Sağlığı Genel Müdürlüğü. Obezite Diyabet ve Metabolik Hastalıklar Daire Başkanlığı, https://hsgm.saglik.gov.tr/tr/obezite/dunyada-obeziteningorulme-sikligi.html (ET:20.07.2020).

36. Türkiye Kalp ve Damar Hastalıkları Önleme ve Kontrol Programı. (2015). Sağlık Bakanlığı Yayın No:988, Ankara, 1516

37. Aktaş, A, Açıkel, SÜ. (2016). "Obezite ve Deri Enfeksiyonları." Türkiye Klinikleri Journal of Cosmetic Dermatology Special Topics, 9 (2), 44-50.

38. Karagöl, A, Özçürümez, G, Taşkıntuna, N, Nar, A. (2014). "Beden kitle indeksinin depresyon ve aleksitimi ile ilişkisi." Anatolian Journal of Psychiatry/Anadolu Psikiyatri Dergisi, 15 (3), 207-213.

39. Altun, S, Ercan, A. (2016). "Obezite Önyargısı." Türkiye Klinikleri Journal of Nutrition and Dietetics-Special Topics, 2 (1), 17-22.

40. Türkiye Fiziksel Aktivite Rehberi. (2014). Türkiye Halk Sağlığı Kurumu, Sağlık Bakanlığı Yayın No:940, Ankara. 